\title{
STRENGTH AND DIMENSION ACCURACY IN FUSED DEPOSITION MODELING : A COMPARATIVE STUDY ON PARTS MAKING USING ABS AND PLA POLYMERS
}

\author{
Yopi Yusuf Tanoto \\ Tenaga Pengajar (Dosen) \\ Universitas Kristen Petra Surabaya \\ Jurusan Teknik Mesin \\ yopi.tanoto@petra.ac.id \\ Juliana Anggono \\ Tenaga Pengajar (Dosen) \\ Universitas Kristen Petra Surabaya \\ Jurusan Teknik Mesin \\ julianaa@petra.ac.id \\ Wesley Budiman \\ Universitas Kristen Petra Surabaya \\ Jurusan Teknik Mesin \\ wesleybudjj8@gmail.com
}

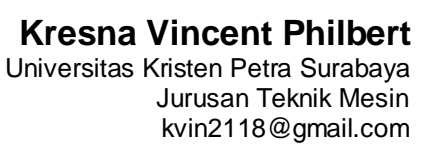

Rapid prototyping is a group of techniques used to quickly scale physical parts or assemblies using three-dimensional computeraided design (CAD) data. The process of $3 D$ printing constructs three-dimensional objects from CAD models, usually by adding layers by a layer of material in a row. Therefore it is also called making addictive manufacturing. Along with the development of rapid prototyping, there are many choices of materials on the market to make parts of $3 D$ printing. The material can be in the solid filament, liquid resin, or powder. Solid filament FDM technology material is the most commonly used by industry - these materials such as $A B S$, PLA, PETG, HIPS, and others. In 3D printing products, several variables can be observed to produces specific responses desirable. Some of the responses are the efficiency of materials, dimensional accuracy of mechanical, and others. This research was conducted to compare ABS and PLA materials in the fused deposition modeling process. The strength and dimensional accuracy are the response that used in this study. The study reports that ABS has more significant tensile strength than PLA. The tensile strength of ABS is 7.66 MPa and 1.79 for PLA. PLA found has a more accurate dimension compare to ABS. Both on length and thickness, deviation of PLA lower than ABS. On a length, deviation of PLA was $0.06 \mathrm{~mm}$ and 0.86 for ABS. On thickness, deviation of PLA was 0.04 and 0.05 for $A B S$.

Keywords: ABS, Fused Deposition Modeling, PLA, Strength

\section{INTRODUCTION}

The effectiveness of product development is an imperative of industry that must be improved. Product cost, time to market, and quality are three effectiveness criteria for a design process [1]. Rapid prototyping (RP) is one of the technologies and methods that are developed to help a designer to make an effective design process. RP is a system that regularly utilized to make a data computer-aided design (CAD) into 3D form with 3D printing technology (additive manufacturing) [2]. Since the introduction of the first rapid commercial prototyping machine known as stereolithography (SLA) in 1986, different types of RP machines with newer systems have been developed and commercialized in different parts of the world [3]. Initially, RP was used in the automotive and aerospace industries, but now it has been widely used in many other industries [4]. 3D Printing, which is one form of RP that makes the process of product development or design, becomes faster [5]. 3D printing is now easy to find in universities and even in primary schools and in the big industry until startup, although with different technology.

Currently, there are many types of 3D printing technology, such as fused deposition modeling (FDM), film transfer imaging (FTI), laminated object manufacturing (LOM), selective laser sintering (SLS), and others. [2]. The RP systems are classified according to the different material technologies they use: powders, plastic filament, or photo-curable liquids. Material selection is essential thing in prototyping. The range of material properties needs to be carefully considered in the process of making a prototype because there are associated trade-offs in mechanical properties, cost, and surface quality [6]. FDM is the most common 
technology used in RP. FDM is relatively cheaper and easy to operate compared to others. FDM is marketed almost half of the total RP [7]. A thermoplastic filament is extruded through a heated die in FDM [5]. Currently, there are many materials options available in the market for FDM 3D printing. There are including HIPS (high impact polyurethane), Nylon, polycarbonate, ABS (acrylonitrile butadiene styrene), PLA (polylactic acid) and others [8]. Among many materials, ABS and PLA are the most widely used. ABS and PLA offer properties that make it useful for creating varied objects, and each has been used in the manufacture of additives for some time [5].

Some researchers have conducted studies on the parameters and materials of 3D printing processes, mainly using FDM technology. Wittbrodt et al. learn about 3D printing components using PLA materials. The parameters used are the color of the PLA and the temperature extruder, while the observed response is the properties (tensile strength and percent crystallinity) of the 3D print component. The presented results show a significant relationship between tensile strength and percent crystallinity of 3D mold samples. Also, there is a significant relationship between percent crystallinity and percent crystallinity [9].

Raut et al. investigated the effect of built orientation on total cost and mechanical properties of the FDM section. They calculated the volume of the printed ABS covert to total cost [10]. Total cost can be minimized by minimizing the main material and its supporting material. Raut et al. conclude that on the yaxis at 0 degrees had good tensile strength and minimum cost and on $\mathrm{x}$-axis had good flexural strength and average cost. The effect of build parameters on processing efficiency and material performance in fused deposition modeling has also studied by Griffiths et al. [11]. The recommendation from this paper was that optimal build parameters for prototyping (dimensional accuracy and where aesthetics take precedence over performance) could incorporate efficiency for cost, energy, and material savings before the production of the part where the parameters would change for optimization of performance.

Tanoto et al. studied the effect of print orientation on processing time, dimensional accuracy, and tensile strength. They were printed using an ABS polymer. The study indicates that the printing process with a third orientation was the fastest [12]. The third orientation is the print orientation that has the most layers and minimum raft. This orientation has a 2432 second processing time of this effect by other effects of 2688 and 2780. In industry, the use of materials is also a factor in the calculation of efficiency. A comparison of PLA and ABS material, which is the most widely used material, is particularly necessary for terms of material strength, and dimensional accuracy does not yet exist. In others to close the gap and continue the research, we performed a comparative study on the accuracy dimension and strength in the parts of ABS and PLA polymers using FDM to study in this research. Choosing the right ingredients for a product is a must. By knowing the comparison, we can choose the right material to use for the intended purpose.

\section{RESEARCH METHODS}

There are many types of polymer with different diameters and colors in FDM filament materials. The typical diameter of materials is $1,75 \mathrm{~mm}$ and $3 \mathrm{~mm}$ with various color choices such as red, white, blue, green, black, and others. The materials used in this research were green PLA and white ABS polymer filaments of $3 \mathrm{~mm}$ BFB (Bytes Bits) and $3 \mathrm{~mm}$ diameter [13,14]. In this research, the type of material color was considered not to affect the response produced, in other words, ignored. ABS is a popular plastic widely used in household appliances and toys [15]. PLA has also been widely used by 3D printing operators or model makers. PLA is different from most thermoplastic polymers. PLA comes from sugar cane or cornflour, which is a renewable resource. The melting point of the PLA is relatively low, 150-160 C, which requires less energy to print with the material. Compared to ABS, PLA has proven to be a safer alternative from toxic [10]. There are five steps to creating a 3D print product using FDM:drawing 3D CAD models, transforming them into STL format, slicing STL formats, building parts in layers, and then finally cleaning and resolving [16].

The 3D CAD software was used to draw 3D CAD and convert it to STL format and Axon V2 to slicing the STL. Specimens were printed using a BFB 3D Touch Double engine or double head (figure 1). Specimen dimension according to ASTM D638-14 was used as reference dimension as figure 2 (115 x $19 \times 4$ $\mathrm{mm}$ ) [17]. The specimens' orientation, as in figure 3, was produced while the FDM printing process. Input parameter or built setting (figure 4) for fill density was $50 \%$ with $0,5 \mathrm{~mm}$ layer thickness. The infill was built-in lattice patterns. The extrusion temperature setting is $180-220^{\circ} \mathrm{C}$, as recommended by the manufacturer. 

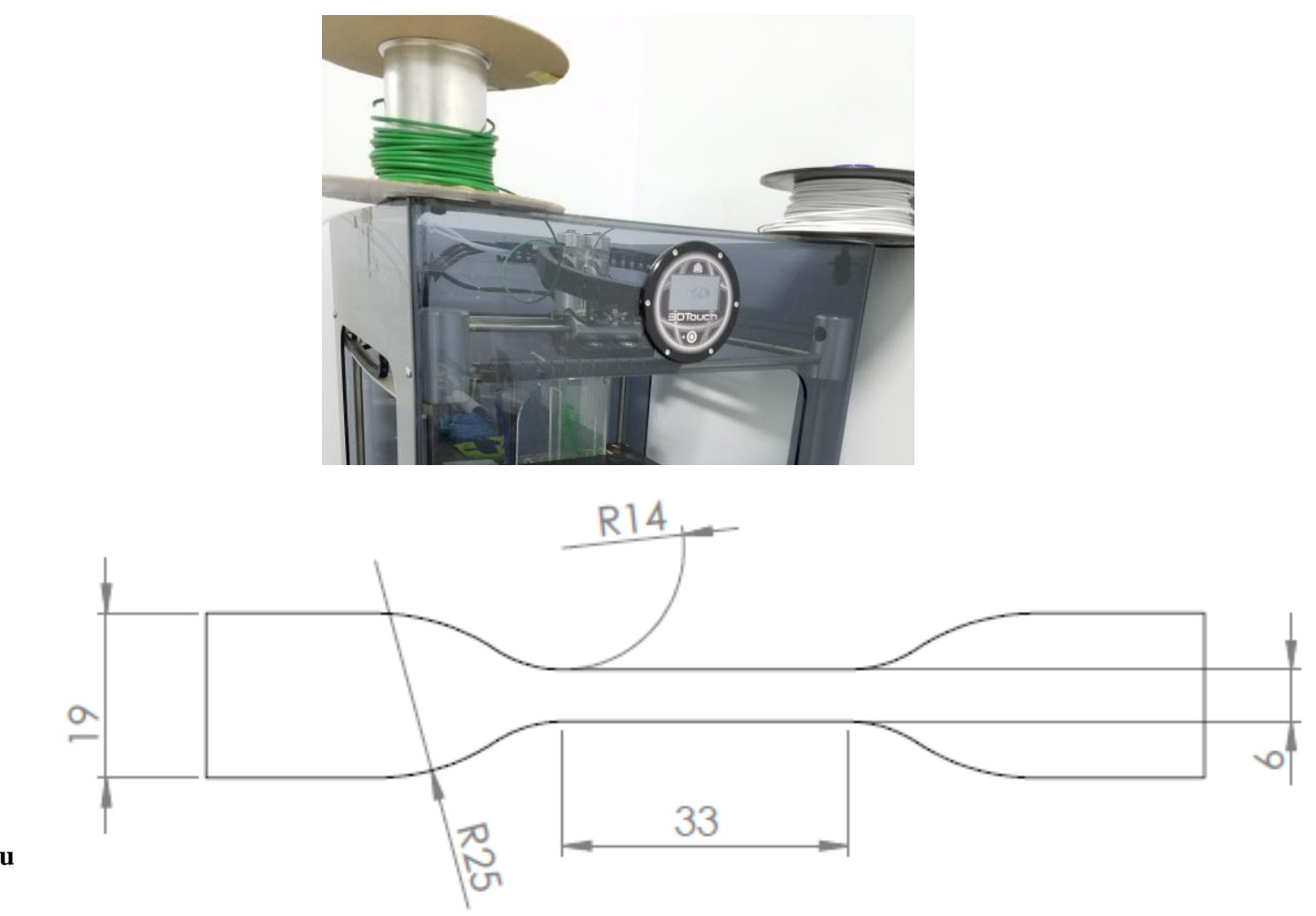

Figu
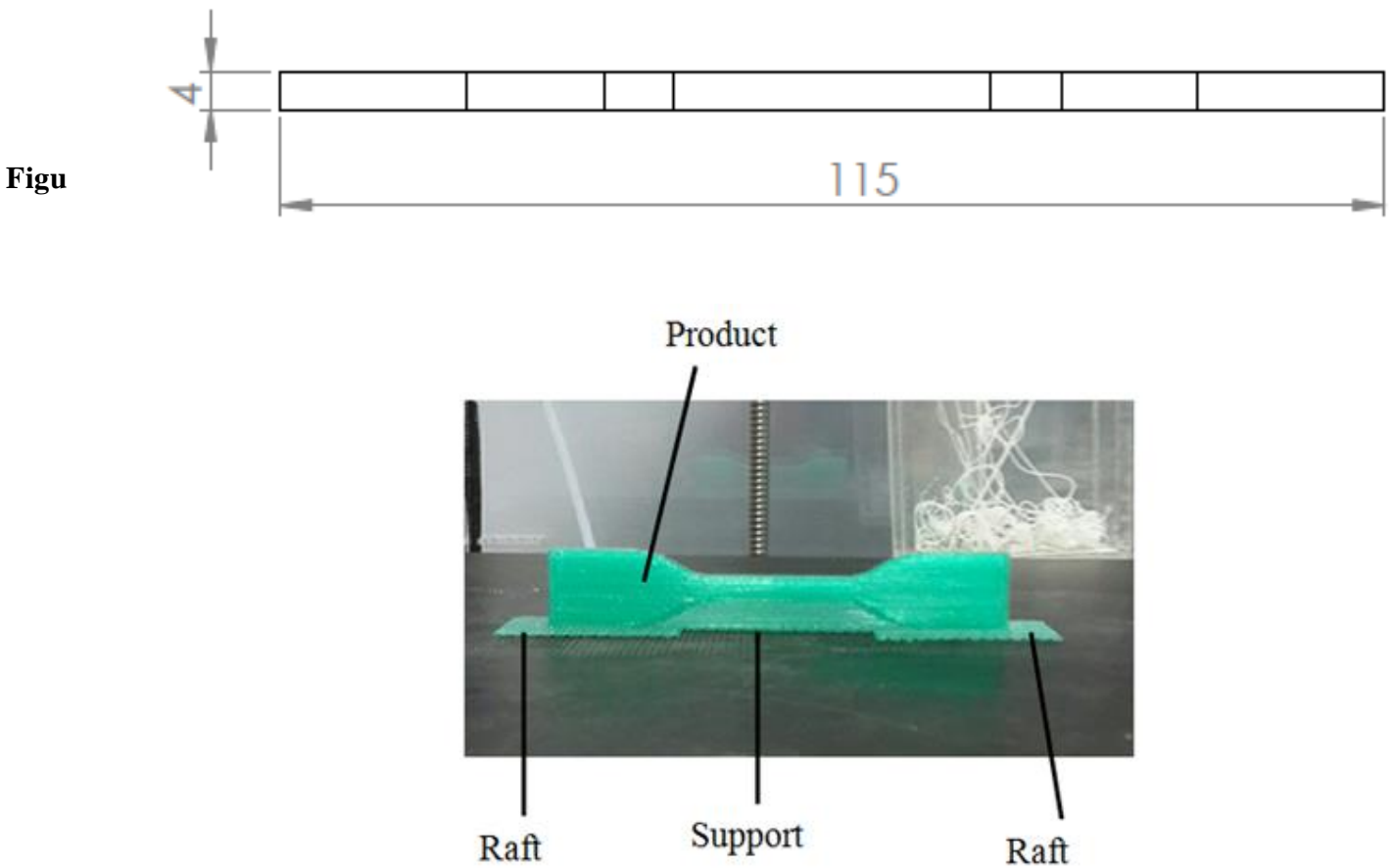

Figure 3. Specimen printing orientation with raft and support 
The dimension was measured with a digital caliper with an accuracy of $0,01 \mathrm{~mm}$. The dimensions measured in this study were only length $(115 \mathrm{~mm})$ and thickness $(4 \mathrm{~mm})$ sections only. The width was not measured because, on one side, there was support and raft. The supporting and raft parts must be removed first in order to get the final shape of the product. The non-standard remove process was feared to make the thickness measurement not objective. To get thickness and length data, 5 points had been determined on the thickness and 3 points on the length as a measurement point. Before performing the tensile test, all specimens were prepared by grinding their surface with the silicon carbide paper with a surface finish surface using grade 1500. The tensile test machine used was Autograph AG 10TE Shimadzu with a capacity of $10 \mathrm{kN}$.

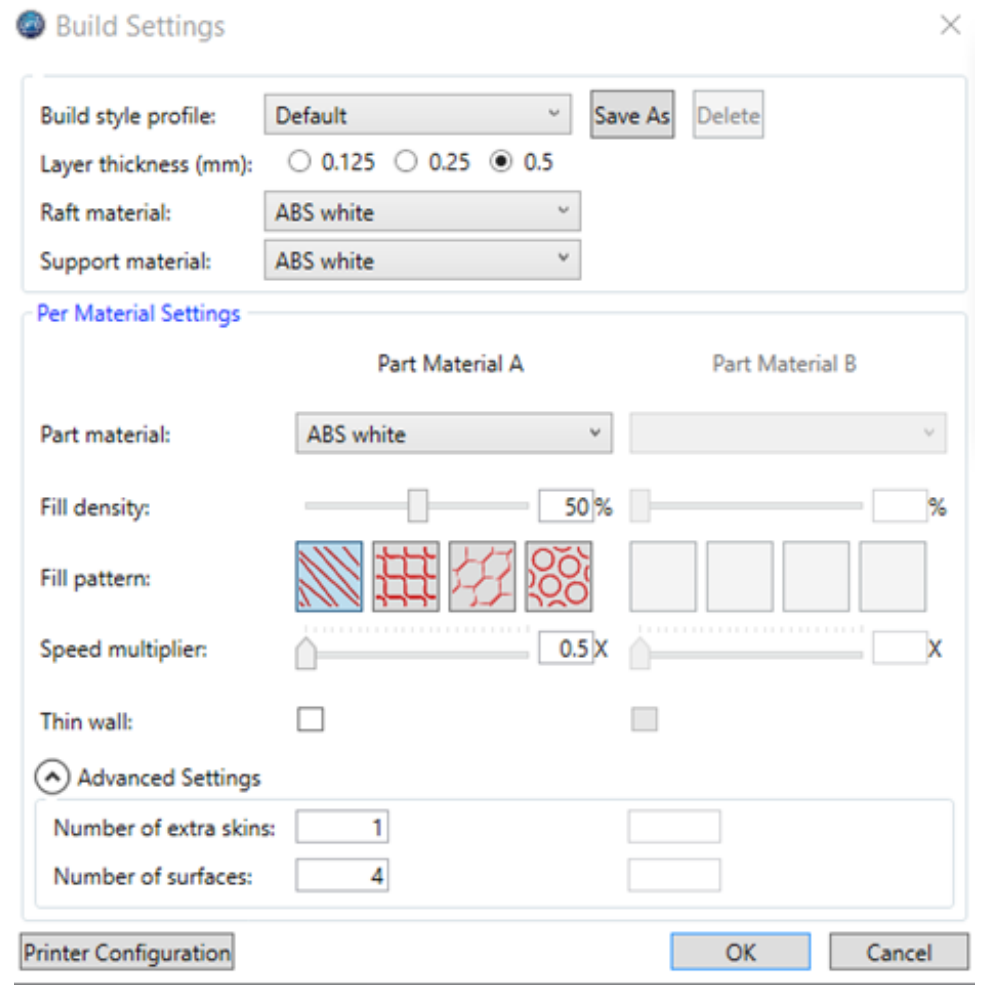

Figure 4. Built setting

\section{RESULT AND DISCUSSION}

There were rafts and support (figure 3) for the printing orientation used in this study. Support was needed because there was a hanging segment from the specimen. In this orientation, specimen height is $19 \mathrm{~mm}$, and the layer thickness is $0,5 \mathrm{~mm}$, so that this specimen had 36 layers. ABS tensile test specimen results and tensile PLA can be seen in figure 5, and the tensile strength value can be seen in figure 6 . From the results, it looked ABS tensile strength greater about 4,2 times compared to PLA, which is 7,66 MPa versus 1,79 MPa. PLA filament had brittle properties compare with ABS filament., Especially on PLA filament that had been stored for a long time, the filament was easily broken compared to ABS, which was more ductile. ABS could be applied to products that require higher strength. PLA filament had brittle properties compare with ABS filament. 


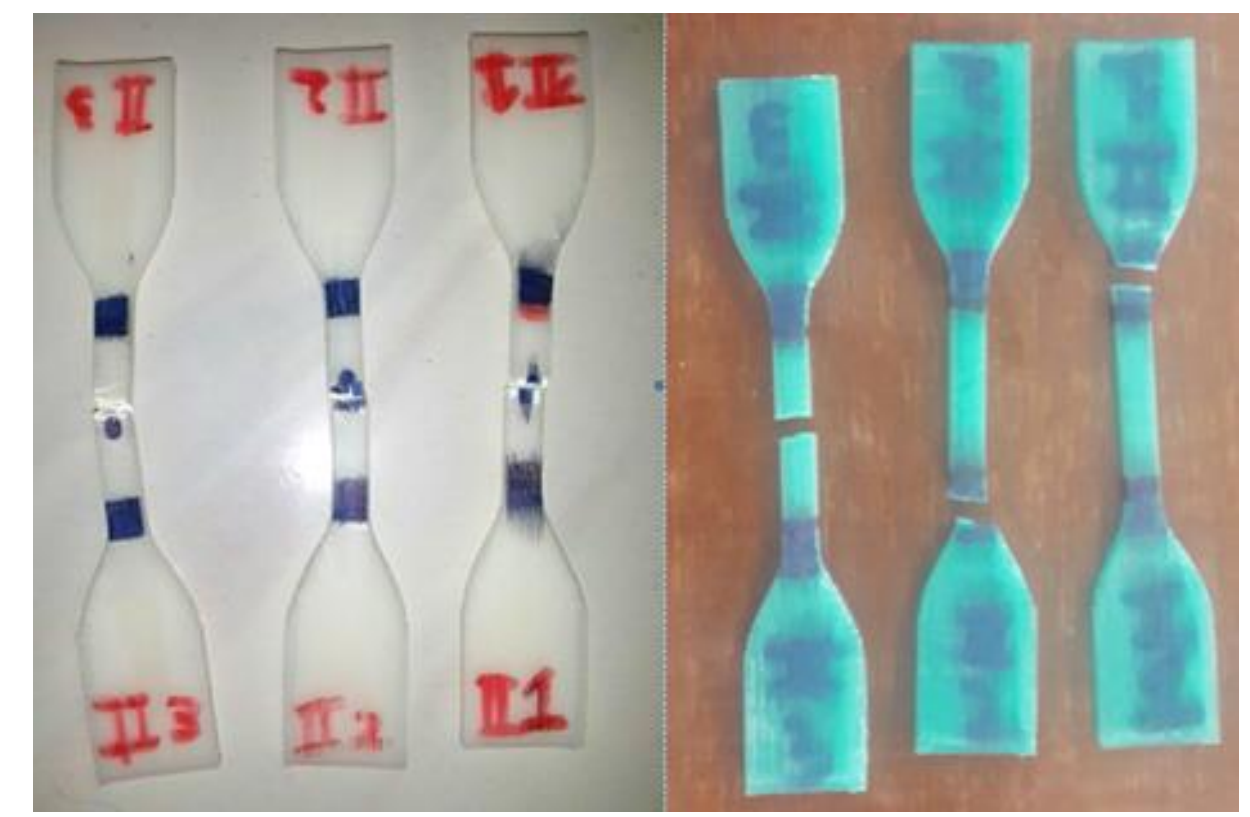

Figure 5.

Tensile test result ABS (left) and PLA (right)

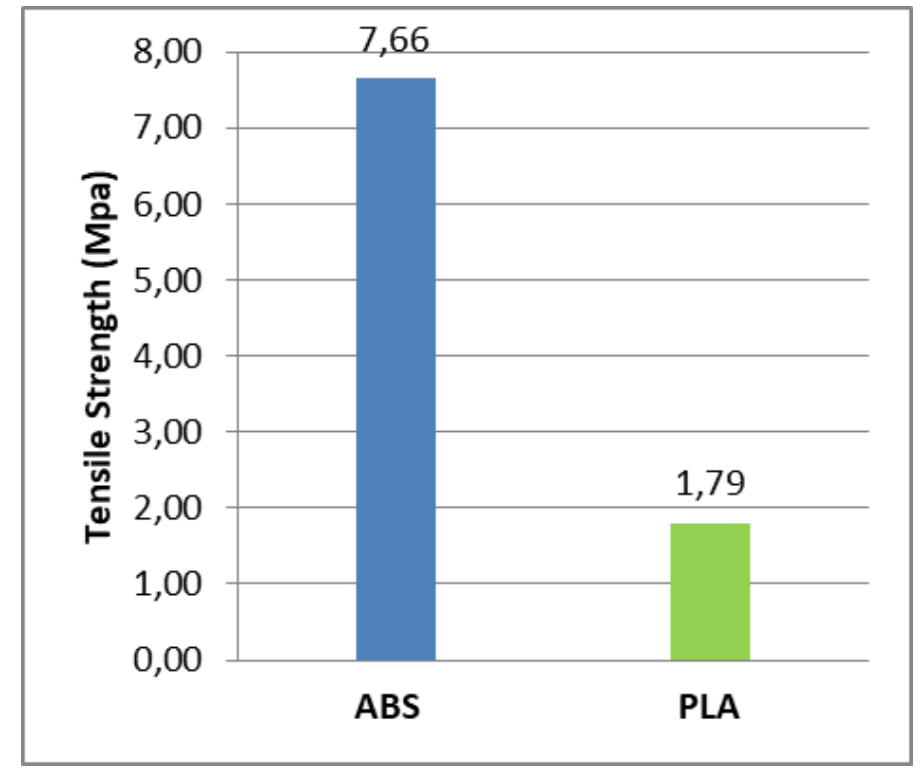

Figure 6. Tensile strength ABS and PLA

Dimensional accuracy was obtained by comparing the measured dimensions (thickness and length) of all printed tensile test specimens with the standard tensile test specimens required by ASTM D638-14.On table 1 can be seen the length measurement results of the ABS specimen. Measurement results on PLA can be seen in table 2. The comparison of the length of the specimen to the measured size (ASTM standard) can be seen in Figure 7. Specimen length that was closest to the standard was found in PLA specimen, i.e., $115,06 \mathrm{~mm}$, or there was a difference of $0,06 \mathrm{~mm}$. The length on the ABS specimen was $114,14 \mathrm{~mm}$. 
Tabel 1. Length of ABS specimen

\begin{tabular}{|c|c|c|c|c|}
\hline \multirow{2}{*}{ SPECIMEN } & \multicolumn{3}{|c|}{ LENGTH ON POINT } & \multirow{2}{*}{ AVERAGE } \\
\hline & $\mathbf{a}$ & b & c & \\
\hline 1 & 114,2 & 114,2 & 114,2 & 114,17 \\
\hline 2 & 114 & 114,2 & 114 & 114 \\
\hline 3 & 114 & 114,2 & 114 & 114,07 \\
\hline \multicolumn{4}{|c|}{ Total Average } & 114,14 \\
\hline
\end{tabular}

Tabel 2. Length of PLA specimen

\begin{tabular}{c|c|c|c|c}
\hline \multirow{2}{*}{ SPECIMEN } & \multicolumn{3}{|c|}{ LENGTH ON POINT } & \multirow{2}{*}{ AVERAGE } \\
\cline { 2 - 4 } & a & b & c & \\
\hline 1 & 115,1 & 115 & 115 & 115,03 \\
\hline 2 & 115 & 115 & 115 & 115 \\
\hline 3 & 115,2 & 115 & 115,2 & 115,13 \\
\hline \multicolumn{5}{|c|}{ Total Average } \\
\hline
\end{tabular}

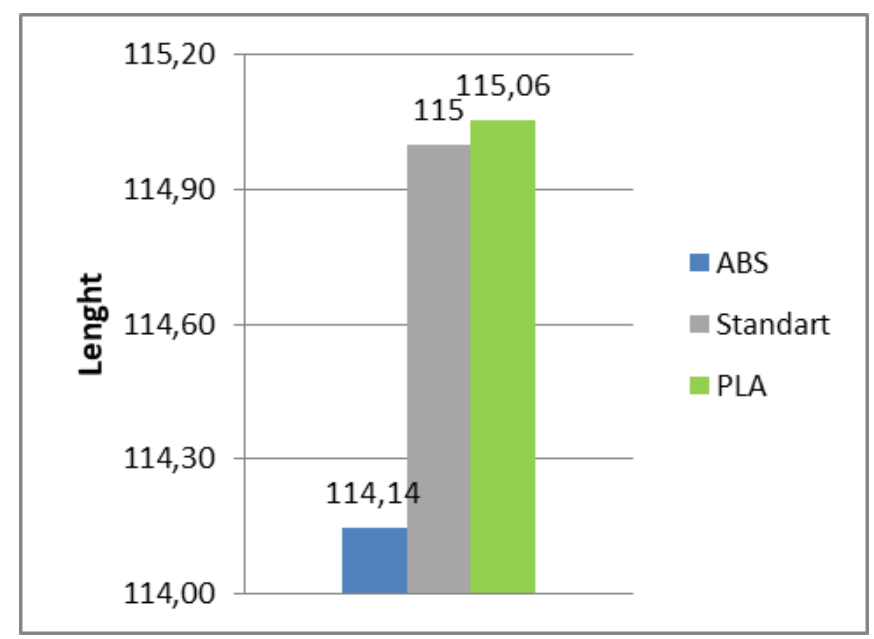

Figure 7. Comparison of ABS and PLA length to standard

The measurement of thickness dimensions form ABS and PLA can be seen in table 3 and table 4. ABS and PLA comparison for thickness can be seen in figure 8. Specimen thickness that was the closest to the standard was found in PLA, i.e. 4,04 mm. In another word, there was a difference of 0,04 mm compare with $\mathrm{ABS}, 0,05 \mathrm{~mm}$. ABS thickness was 4,05 $\mathrm{mm}$.

Tabel 3. Thickness of ABS specimen

\begin{tabular}{c|c|c|c|c|c|c}
\hline \multirow{2}{*}{ SPECIMEN } & \multicolumn{7}{c|}{ THICKNESS ON POINT } & \multirow{2}{*}{ AVERAGE } \\
\cline { 2 - 7 } & $\mathrm{a}$ & $\mathrm{b}$ & $\mathrm{c}$ & $\mathrm{d}$ & $\mathrm{e}$ & \\
\hline 1 & 4,77 & 3,88 & 3,84 & 3,85 & 3,88 & 4,04 \\
\hline 2 & 4,87 & 3,9 & 3,88 & 3,86 & 3,88 & 4,08 \\
\hline 3 & 4,74 & 3,84 & 3,85 & 3,84 & 3,87 & 4,03 \\
\hline \multicolumn{7}{c}{ Total Average } \\
\hline
\end{tabular}


Tabel 4. Thickness of PLA specimen

\begin{tabular}{c|c|c|c|c|c|c}
\hline \multirow{2}{*}{ SPECIMEN } & \multicolumn{7}{|c|}{ THICKNESS ON POINT } & \multirow{2}{*}{ AVERAGE } \\
\cline { 2 - 6 } & $\mathrm{a}$ & $\mathrm{b}$ & $\mathrm{c}$ & $\mathrm{d}$ & $\mathrm{e}$ & \\
\hline 1 & 4,05 & 4,07 & 4,05 & 4,03 & 4,03 & 4,05 \\
\hline 2 & 4,06 & 4,05 & 4,03 & 4,02 & 4,01 & 4,03 \\
\hline 3 & 4,05 & 4,07 & 4,04 & 4,05 & 4,06 & 4,05 \\
\hline \multicolumn{7}{c}{ Total Average } \\
\hline
\end{tabular}

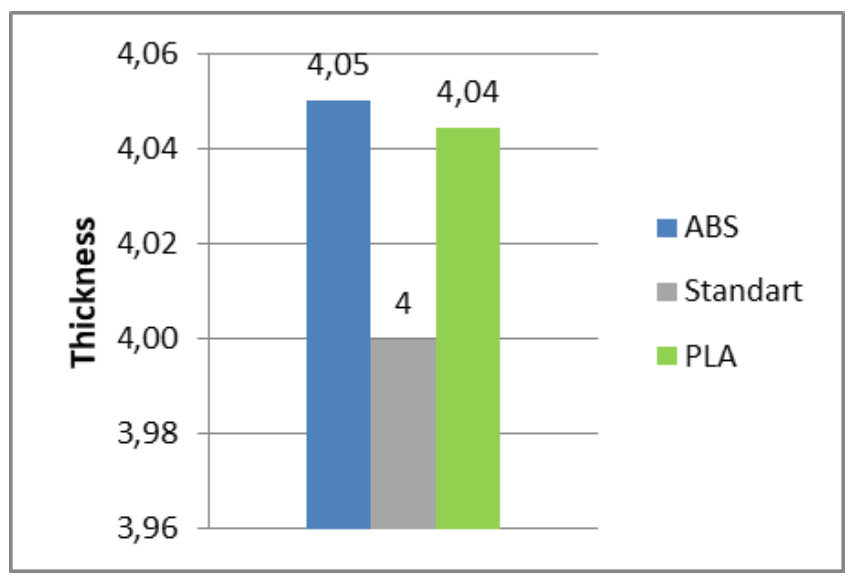

Figure 8. Comparison of ABS and PLA thickness to standard

\section{CONCLUSION}

The ultimate tensile strength and dimensional accuracy of 3D printed materials are investigated. From experiment results and tests performed, it could be concluded that ABS had bigger tensile strength, i.e. 7,66 MPa than PLA, i.e. 1,79 MPa. In dimensional accuracy, PLA had the smallest difference in dimension both on length and thickness of its own in comparison to the required dimension by ASTM D638-14. The difeferences were 0,4 $\mathrm{mm}$ for thickness and 0,06 for length. ABS should be used for components that require more strength, while PLA was used when accuracy was required in making a component. Further studies can be carried out on other properties such as flexural strength, impact, and others.

\section{ACKNOWLEDGEMENTS}

This work was supported by Lembaga Penelitian dan Pengabdian Masyarakat (Research and Community Services Institute) Petra Christian University, Indonesia, as part of Hibah Penelitian Internal 2016-2017 (Internal Research Grant 2015-2017) program. Authors would like to express their gratitude toward the institutions.

\section{REFERENCES}

[1] ULMAN, D. G., The Mechanical Design Process, 4 ed., Singapore, McGraw-Hill.Inc., 2010.

[2] KALPAKJIAN, S., \& SCHMID, S. R., Manufacturing Engineering and Technology 7 ed., Chicago, Pearson, 2013.

[3] LEE, B.H., ABDUlLAH, J. and KHAN, Z.A., "Optimization of Rapid Prototyping Parameters for Production of flexible ABS Object”, Journal of Materials Processing Technology, v. 169, pp. 54-61, Feb. 2005.

[4] KOCHAN, D., KAI, C.C. and ZHAOHUI, D., "Rapid Prototyping Issues in the 21st Century", Computers in Industry, v. 39, pp. 3-10, JUN. 1999.

[5] LESKO, J., Industrial Design: Materials and Manufacturing Guide, New Jersey, John Wiley \& Sons Inc., 2011.

[6] HALlGRIMSSON, B., Prototyping ang Model Making for Product Design, London, Laurence King Publishing, 2012. 
[7] ANITHA, R., ARUNACHALAM, S. and RADHAKRISHAN, P., "Critical Parameters Influencing the Quality of Prototypes in Fused Deposition Modeling”. Journal of Materials Processing Technology, v. 118, pp. 385-388, Dec. 2001.

[8] HUNT, E.J., ZHANG, C., ANZALONE, N. and PEARCE, J.M., "Polymer Recycling Codes for Distributed Manufacturing with 3-D Printers", Resource, Conserve and Recycle, v. 97, pp. 24-30, Apr. 2015.

[9] WITTBORDT, B. and PEARCE, J.M., "The Effect of PLA Color on Material Properties of 3-D Printed Components", Addictive Manufacturing, v. 8, pp. 110-116, Oct. 2015.

[10] RAUT, S., JATTI, V.K.S., KHEDKAR, N.K. and SINGH, T.P., "Investigation of the Effect of Built Orientation on Mechanical Properties and Total Cost of FDM Parts", In: proceeding of the 3rd International Conference on Materials Processing and Characterization Procedia Materials Science, v. 6, pp. 1625-1630, Hyderabad, March. 2014.

[11] GRIFFITHS, C.A., HOWARTH, J., ROWBOTHAM, DE-ALMEIDA, G. and REESA, A., "Effect of Build Parameters on Processing Efficiency and Material Performance in Fused Deposition Modelling", In: proceeding of The Second CIRP Conference on Biomanufacturing, Procedia CIRP, v. 49, pp. 28 32, Manchester, Sept. 2016

[12] TANOTO, Y.Y., ANGGONO, J., SIAHAAN, I.H. and BUDIMAN, W., "The Effect of Orientation Differences in Fussed Deposition Modeling of ABS Polymer on the Processing Time, Dimension, Accuracy, and Strength", In: Proceeding of This International Conference on Engineering, Science and Nanotechnology, American Institute of Physics, v. 1788, pp. 030051, Solo, Jan. 2017.

[13] Safety Data Sheet ABS [online]. Available from: http://infocenter.3dsystems.com (accessced 03.16.17).

[14] Safety Data Sheet PLA [online]. Available from: http://infocenter.3dsystems.com (accessced 03.16.17).

[15] BUDMEN, I., \& ROTOLO, A., The book on 3D Printing, North Charleston, Create Space Independent Publishing Platform, 2013.

[16] NIDAGUNDI, V.B., KESHAVAMURTHY, R. and PRAKASH, C.P.S., "Studies on Parametric Optimization for Fused Deposition Modeling Process", In: proceeding of 4th International Conference on Materials Processing and Characterization, Materials Today: Proceedings 2, pp.1691 - 1699, Andhra Pradesh. Feb. 2015.

[17] ASTM D 638 - 02a, Standard Test Method for Tensile Properties of Plastic, ASTM, 2002. 